\section{OPTICAL FIBRE POLISHING WITH A MOTOR-DRIVEN POLISHING WHEEL}

Indexing terms: Optical fibres, Optical transmission

The polishing of optical fibres is demonstrated using an abrasive polishing wheel. The approach requires that only the fibre itself is polished and allows arbitrarily long interaction lengths to be generated with losses of less than $0 \cdot 1 \mathrm{~dB}$.

Introduction: A whole range of optical fibre componentsfrom couplers to modulators and switches-can be achieved by interacting with the evanescent field of an optical fibre. ${ }^{1,2}$ Such evanescent interaction has been obtained by removing the fibre's cladding through polishing. Typically the fibre is fixed in a groove already prepared in a quartz block and both the block and the fibre have to be polished to produce a large optically flat surface. ${ }^{3}$ Here we report on a novel fibre polishing approach where only the fibre itself is polished on a motor-driven polishing wheel. This process, which can have close to $100 \%$ success rate, dramatically reduces the polishing time and can provide a uniform polished region of arbitrary length.

Fibre polishing: The fibre (locally stripped) is suspended under slight tension over a lubricated polishing wheel as shown in Fig. 1. The polished length can be altered by changing the

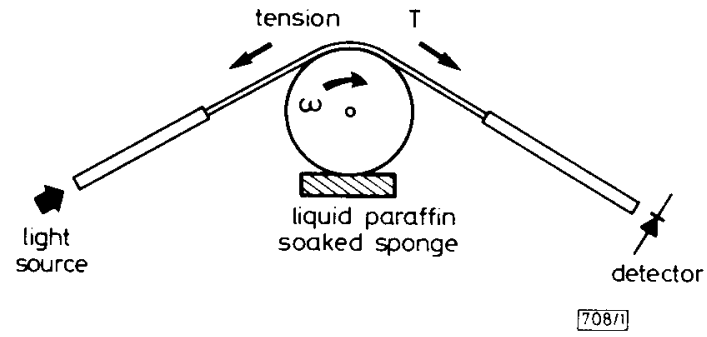

Fig. 1 Schematic diagram of fibre polishing arrangement

contact angle of the fibre on the wheel, or by using a polishing wheel of different diameter. Under our polishing conditions, where the wheel rotates at $50-100 \mathrm{rev} / \mathrm{min}$, the tension on the fibre is approximately $0.2 \mathrm{~N}$ and the wheel is lubricated with liquid paraffin, the radial force on the wheel from the fibre is essentially uniform over the contact length and the fibre polishes uniformly over that length. Fig. 2 shows the longitudinal
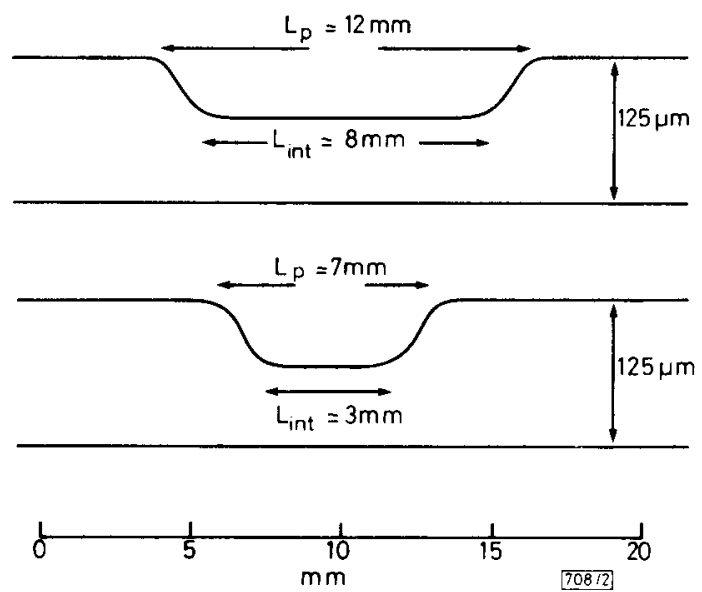

Fig. 2 Longitudinal profile for two polished flats

TOP Polished length approximately $12 \mathrm{~mm}$

BOTTOM Polished length approximately $7 \mathrm{~mm}$

profile of two polished flats on a single-mode fibre for two different contact lengths produced on a wheel of $2.5 \mathrm{~cm}$ diameter as measured under a travelling microscope. It is found that, indeed, the polished flat is uniform except for the transitions at each end of the polished region.

On examining Fig. 2 in more detail it is found that the lengths of the end transition regions are the same irrespective of the overall polished length. For the $125 \mu \mathrm{m}$ diameter silica fibre used, this transition length was $2 \mathrm{~mm}$ at each end. So that for an overall polished length of $12 \mathrm{~mm}$ the optical interaction length would be approximately $8 \mathrm{~mm}$ while for an overall polished length of $7 \mathrm{~mm}$ the optical interaction length would be approximately $3 \mathrm{~mm}$. The abrasive wheel used was a Van Moppes IDP diamond impregnated resin polishing wheel with particle sizes of 2-6 $\mu \mathrm{m}$.

Optical properties: As the fibre is being polished the wheel is lubricated with a high-index liquid paraffin which plays the additional role of mode stripper when the polished flat

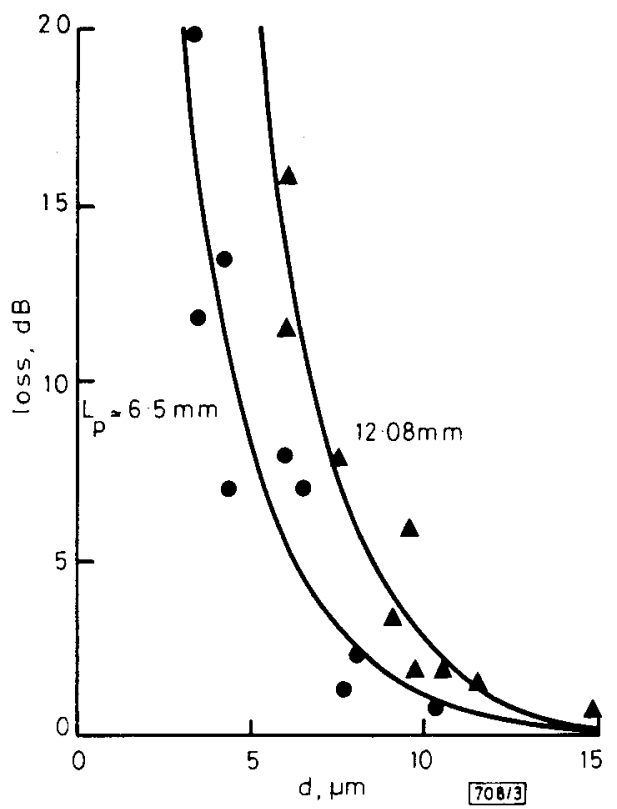

Fig. 3 Loss calibration curves (for fibre mentioned in text) as function of distance from fibre axis for two different polished lengths

Also shown are experimental points
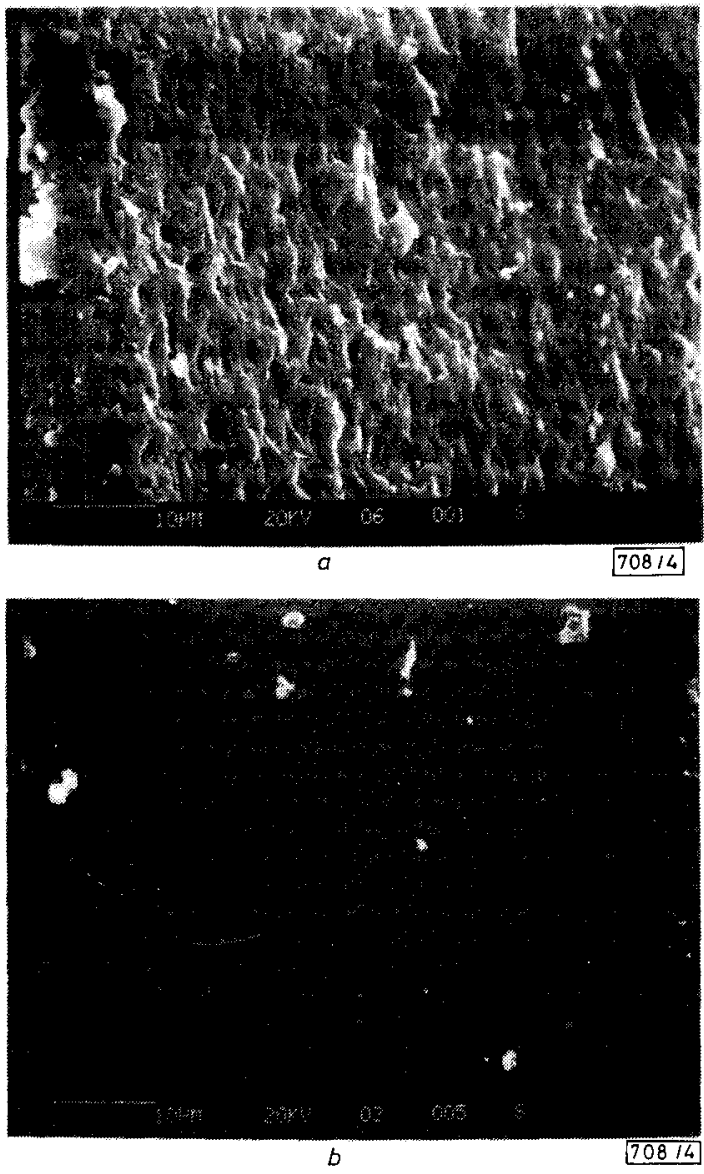

Fig. 4 SEM photographs for a polished flat

a Directly from diamond polishing wheel

$b$ After polishing with cerium oxide for $5 \mathrm{~min}$ 
approaches the core. The measured loss of power as a function of distance from the fibre axis is shown in Fig. 3 for two different overall polished lengths. The fibre in this case was single-moded with a cutoff wavelength of $1 \cdot 2 \mu \mathrm{m}$, a core radius of $4 \mu \mathrm{m}$ and an outer diameter of $125 \mu \mathrm{m}$. A laser diode operating at $1.3 \mu \mathrm{m}$ and a germanium photodetector were used to monitor the loss.

To measure the polished depth the fibre was cleaved and the cross-section examined under a microscope. The curves in Fig. 3 represent an exponential 'best fit' to the experimental data which are also shown. Fig. 3 provides a useful calibration; in practice, it would be the 'level of interaction' or loss for a given length which would provide the deciding factor as to whether the polished depth is satisfactory for a specific application.

An SEM photograph of a polished flat taken straight off the diamond polishing wheel is shown in Fig. 4a. This flat exhibited a throughput loss of $10 \mathrm{~dB}$ in liquid paraffin and approximately $0.4 \mathrm{~dB}$ with the liquid paraffin removed. The residual loss is a result of scattering due to surface imperfections. The scatter loss can be reduced by further polishing with a finer polishing paste on the wheel or by fire polishing Fig. $4 b$ shows SEM photographs of polished flats which had been further polished for five minutes on the wheel impreg nated with cerium oxide. The surface is improved to the extent that scatter losses of less than $0.1 \mathrm{~dB}$ could be routinely achieved.

Discussion: The advantages of this new method over the polished block approach are:

(i) Polishing times of approximately $1-5 \mathrm{~min}$. (ii) Polished lengths can be arbitrarily long, e.g. we have repeatedly achieved a length of $3 \mathrm{~cm}$ with a $6 \mathrm{~cm}$ diameter wheel, with no difficulty.

(iii) The polished fibre can be further processed at high temperature yielding an added flexibility in device design.

(iv) The polished flat opens up the possibility for fused evanescent multiport elements yielding stable devices in depressed cladding fibres and in $\mathrm{HiBi}$ fibres as well as matched cladding fibres.

There are numerous applications of polished fibres in evanescent devices and couplers. However, our purpose here is not to present a shopping list of components but to present this new polishing approach as an additional technique for the construction of fibre devices which should complement the use of polished blocks, tapers and etching for field access in optical fibres.

C. D. HUSSEY

\section{J. D. MINELLY}

26th May 1988

Optical Fibre Group

Department of Electronics \& Computer Science

University of Southampton

Southampton SO9 $5 \mathrm{NH}$, United Kingdom

\section{References}

1 BERGH, R. A., KOTLER, G., and SHAW, H. J.: 'Single-mode fibre optic directional coupler', Electron. Lett., 1980, 16, pp. 260-261

2 EІCкноF,, w.: 'In-line fibre optic polariser', Electron. Lett., 1980, 16, pp. $762-763$

3 NICHOLLS, $\mathbf{s}$. T.: 'Automatic manufacture of polished single-mode fibre directional coupler', Electron. Lett., 1985, 21, pp. 825-826 